10 Simmonds P. SSE: a nucleotide and amino acid sequence analysis platform. BMC Res Notes 2012; 5: 50.

11 Tamura K, Dudley J, Nei M, et al. MEGA4: Molecular Evolutionary Genetics Analysis (MEGA) software version 4.0. Mol Biol Evol 2007; 24: 1596-1599.

12 Flight WG, Bright-Thomas RJ, Tilston P, et al. Chronic rhinovirus infection in an adult with cystic fibrosis. $J$ Clin Microbiol 2013; 51: 3893-3896.

13 Jartti T, Lehtinen P, Vuorinen T, et al.. Persistence of rhinovirus and enterovirus RNA after acute respiratory illness in children. J Med Virol 2004; 72: 695-699.

14 Kling S, Donninger H, Williams Z, et al. Persistence of rhinovirus RNA after asthma exacerbation in children. Clin Exp Allergy 2005; 35: 672-678.

15 Kieninger E, Regamey N. Rhinoviruses: markers of, or causative for, recurrent wheeze and asthma? Eur Respir J 2012; 39: 238-239.

\title{
Referred shoulder pain (C4 dermatome) can adversely impact diaphragm pacing with intramuscular electrodes
}

To the Editor:

Diaphragm pacing is an alternative to mechanical ventilation in patients with high cervical cord damage $(>\mathrm{C} 4$ dermatome). It brings clinical benefits and reduces health costs [1-3]. It is also indicated in certain cases of central hypoventilation [4]. Two types of diaphragm pacing devices are commercially available. With intrathoracic phrenic stimulation, electrodes are implanted around the phrenic nerves in the thorax (Avery Biomedical, Commack, NY, USA; and Atrotech, Tampere, Finland). Nerve dissection during a video-assisted mini-thoracotomy allows intimate contact of the stimulating electrodes with the nerve [5]. Stimulating currents typically range between $0.3-3.5 \mathrm{~mA}[6]$. With intradiaphragmatic stimulation, hook wire electrodes are laparoscopically implanted in the diaphragm in the vicinity of the phrenic nerve termination (Synapse Biomedical, USA) [in 5]. Stimulating currents typically range between 5-20 mA. In quadriplegic patients, intradiaphragmatic phrenic stimulation is effective [7] and has been advocated as easier to implement and less expensive than its intrathoracic counterpart [5]. In patients who retain spontaneous diaphragm activity, this approach is appealing because it is devoid of the theoretical risk of procedure-induced phrenic nerve damage associated with the intrathoracic route. For these reasons, we implanted intradiaphragmatic phrenic stimulators in four hypoventilation patients after the device was authorised in France in 2010. In France, both intrathoracic and intradiaphragmatic diaphragm pacing are authorised and reimbursed by social security in quadriplegia and central hypoventilation and are managed at a single multidisciplinary centre nationwide.

This report is motivated by the fact that, in these four cases, diaphragm pacing efficiency was compromised and clinical management complicated by phrenic stimulation associated pain. We did not observe this in comparable patients implanted intrathoracically.

We describe nine patients (table 1) who all had central hypoventilation, documented diaphragm responses to phrenic stimulation and preserved sensitivity on clinical examination (present and symmetrical pin-prick and light-touch sensations on routine systematic neurological examination). They reported normal pain perception in daily life. Phrenic stimulator implantations were performed over a 15-year period. Patients 1-5 were implanted intrathoracically (single surgeon, group 1) and patients 6-9 were implanted intradiaphragmatically (single surgeon, group 2). Patients $1-3$ were implanted first, then patients 6-9 and then patients 4-5. Patients 1-3 were implanted in the context of an externally approved research [2]. The other patients were implanted on clinical indications. They gave consent to the anonymous use of their clinical data, which was approved by the Institutional Review Board of the Société de Pneumologie de Langue Française (decision \#2014-048). The reversal of hypoventilation-related pulmonary hypertension by intradiaphragmatic phrenic stimulation in patient 6 has been described elsewhere [8].

Phrenic stimulation-induced pain was defined as pain: 1) reported spontaneously or in response to oriented questioning, 2) appearing upon start of pacing and disappearing more or less rapidly upon its discontinuation, 3) involving a pathophysiologically logical territory (upper abdominal quadrants, inferior 
TABLE 1 Characteristics of the patient and diaphragm pacing outcomes

\begin{tabular}{|c|c|c|c|c|c|c|c|c|}
\hline Patient & Sex & $\begin{array}{l}\text { Age at } \\
\text { stimulation } \\
\text { years }\end{array}$ & Clinical context & $\begin{array}{l}\text { Reason for } \\
\text { implantations }\end{array}$ & $\begin{array}{l}\text { Type of } \\
\text { stimulation }\end{array}$ & $\begin{array}{l}\text { Device linitial } \\
\text { intensity) }{ }^{\#} \mathrm{~mA}\end{array}$ & $\begin{array}{l}\text { Stimulation-related } \\
\text { shoulder(s) pain }\end{array}$ & $\begin{array}{l}\text { 1-year clinical } \\
\text { outcome }\end{array}$ \\
\hline 1 & Female & 14 & $\mathrm{CCHS}^{\Uparrow}$ & $\begin{array}{l}\text { Permanent ventilator } \\
\text { dependency }\end{array}$ & Intrathoracic & $\begin{array}{c}\text { Atrostim }^{+} \text {: } \\
\text { right not functional, left } 1.0\end{array}$ & $\mathrm{No}^{\S}$ & $\begin{array}{l}\text { Full weaning yes, } \\
\text { hypoventilation no, } \\
\text { corrected PH NA }\end{array}$ \\
\hline 2 & Male & 20 & $\mathrm{CCHS}^{f}$ & $\begin{array}{l}\text { Permanent ventilator } \\
\text { dependency/severe } \mathrm{PH} \\
\text { with cor pulmonale }\end{array}$ & Intrathoracic & Atrostim $^{+}$: right 1.3 , left 0.5 & No & $\begin{array}{l}\text { Full weaning yes, } \\
\text { hypoventilation no, } \\
\text { corrected } \mathrm{PH} \text { yes }\end{array}$ \\
\hline 3 & Male & 25 & Post-neurosurgery $\# \#$ & $\begin{array}{l}\text { Permanent ventilator } \\
\text { dependency }\end{array}$ & Intrathoracic & Atrostim $^{+}$: right 0.5 , left 0.5 & No & $\begin{array}{l}\text { Full weaning yes, } \\
\text { hypoventilation no, } \\
\text { corrected PH NA }\end{array}$ \\
\hline 4 & Male & 17 & $\mathrm{CCHS}^{\text {กึก }}$ & $\begin{array}{l}\text { Permanent ventilator } \\
\text { dependency }\end{array}$ & Intrathoracic & Atrostim ${ }^{+}:$right 0.5 left 0.5 & $\mathrm{No}^{++}$ & $\begin{array}{l}\text { Full weaning yes, } \\
\text { hypoventilation no, } \\
\text { corrected PH NA }\end{array}$ \\
\hline 5 & Male & 59 & $\begin{array}{l}\text { Probable ischaemic } \\
\text { brainstem lesions, } \\
\text { mitochondrial cytopathy }\end{array}$ & $\begin{array}{l}\text { Permanent ventilator } \\
\text { dependency }\end{array}$ & Intrathoracic & Atrostim ${ }^{+}$: right 2.2, left 2.2 & No & $\begin{array}{l}\text { Full weaning yes, } \\
\text { hypoventilation no } \\
\text { corrected PH NA }\end{array}$ \\
\hline 6 & Female & 28 & $\mathrm{CCHS}^{\S \S}$ & $\begin{array}{l}\text { Permanent ventilator } \\
\text { dependency/severe PH } \\
\text { with cor pulmonale }\end{array}$ & Intradiaphragm. & $\begin{array}{l}\text { NeurRxDPSff: } \\
\text { right } 18 \text {, left } 18\end{array}$ & $\begin{array}{l}\text { Yes, requiring: reduced } \\
\text { intensities (to } \sim 10 \mathrm{~mA} \text {, and } \\
\text { switching off one electrode), } \\
\text { pregabalin then gabapentin } \# \# \#\end{array}$ & $\begin{array}{l}\text { Full weaning yes, } \\
\text { hypoventilation yes, } \\
\text { corrected PH yes }\end{array}$ \\
\hline 7 & Female & 67 & $\begin{array}{l}\text { Post-cervical spinal } \\
\text { surgery, severe } \\
\text { tetraparesis }\end{array}$ & $\begin{array}{l}\text { Permanent ventilator } \\
\text { dependency }\end{array}$ & Intra diaphragm. & $\begin{array}{l}\text { NeurRxDPSff: } \\
\text { right 21, left } 21\end{array}$ & $\begin{array}{l}\text { Yes requiring: reduced } \\
\text { intensities (<10 mA) opioids } \\
\text { (oral+transcutaneous) }\end{array}$ & $\begin{array}{l}\text { Full weaning no, } \\
\text { hypoventilation no, } \\
\text { corrected PH NA }\end{array}$ \\
\hline 8 & Male & 44 & Post-neurosurgery & $\begin{array}{l}\text { Permanent ventilator } \\
\text { dependency }\end{array}$ & Intra diaphragm. & $\begin{array}{l}\text { NeurRxDPS } f f \\
\text { right } 23 \text {, left } 23\end{array}$ & $\begin{array}{l}\text { Yes }^{+++} \text {requiring: reduced } \\
\text { intensities (to } \sim 15 \mathrm{~mA} \text { ), } \\
\text { transcutaneous opioids } \\
\text { +pregabalin+gabapentin } \\
\text { then gabapentin alone }\end{array}$ & $\begin{array}{l}\text { Full weaning yes, } \\
\text { hypoventilation yes, } \\
\text { corrected PH NA }\end{array}$ \\
\hline 9 & Female & 44 & $\begin{array}{l}\text { Post-cervical spinal } \\
\text { surgery, severe } \\
\text { tetraparesis }\end{array}$ & $\begin{array}{c}\text { Permanent ventilator } \\
\text { dependency }\end{array}$ & Intra diaphragm. & $\begin{array}{l}\text { NeurRxDPSff: } \\
\text { right } 16 \text {, left } 11\end{array}$ & $\begin{array}{l}\text { Yes requiring: reduced } \\
\text { intensities (<10 mA), opioids } \\
\text { (oral+transcutaneous) } \\
\text { +duloxetine }\end{array}$ & $\begin{array}{l}\text { Full weaning no, } \\
\text { hypoventilation yes, } \\
\text { corrected PH NA }\end{array}$ \\
\hline
\end{tabular}

CCHS: congenital central hypoventilation syndrome; PH: pulmonary hypertension; NA: not applicable. \#: stimulation intensity as determined post-operatively upon initiation of diaphragm pacing; phrenic stimulators rely on several electrodes for each phrenic nerve: the values provided in this table correspond to the maximal intensities noted on each side (for intrathoracic stimulation the value noted is the difference between "stimulation" and "threshold" intensities). ": PHOX2B frameshift mutation. ${ }^{+}$: Atrotech (Tampere, Finland) type 1 for patients 1 and 2, and type 2 for patients 3-5. $\$$ : this patient reported right referred shoulder pain upon initiation of pacing, which disappeared after changing stimulation frequency; no need to reduce intensity or use antalgic drugs. $f$ : PHOX2B mutation unknown (died 1999, before the description of the genetic basis of CCHS). \#\#: resection of medullary ependymoma. "17: PHOX2B 20/27 alanine expansion. ${ }^{++}$: this patient reported bouts of right and left stitches in the upper abdominal quadrants at the beginning of pacing that were interpreted as resulting from excessive muscular strain induced by stimulation of a non-atrophic diaphragm and disappeared over time; no shoulder pain; no need to use antalgic drugs. ${ }^{\S}$ : PHOX2B $20 / 26$ alanine expansion.

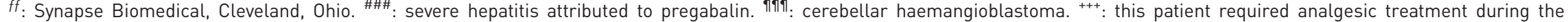
3 years that followed implantation; after 3 years, analgesics could be discontinued without reducing stimulation intensity. 
thoracic regions, neck/shoulder), and 4) requiring both a reduction in stimulation intensity and analgesic medications to pursue pacing. Full ventilatory autonomy (weaning from mechanical ventilation) was defined as the possibility for the patient to remain on diaphragm pacing $24 \mathrm{~h}$ a day, irrespective of the actual use of the device and of arterial carbon dioxide tension $\left(\mathrm{PaCO}_{2}\right)$. Some patients reached ventilatory autonomy a few days after implantation. In others, a weaning protocol similar to that used in quadriplegia was followed (incremental daily stimulation sessions guided on tidal volume maintenance and clinical tolerance) for 2-9 weeks. For the purpose of this particular report, the ventilatory autonomy outcome was assessed 1 year after implantation. Persistent hypoventilation was defined as hypercapnia $\left(\mathrm{PaCO}_{2} \geqslant 45 \mathrm{mmHg}\right)$ under pacing. Full correction of pulmonary hypertension was defined as the return of echocardiographically measured systolic arterial pressure $<30 \mathrm{mmHg}$. Outcomes were compared using $2 \times 2$ contingency tables and Fischer's exact test with $\mathrm{p}<0.05$ considered significant.

Phrenic stimulation-induced pain was never noted in group 1, while it was always present in group 2 $(\mathrm{p}=0.0079)$. It consisted in unilateral or bilateral neck and shoulder pain (C3-C5 dermatomes). Pain was generally described as an aching and/or burning sensation that started immediately or quasi so after switching the stimulator on and could last several minutes after switching it off. It was not associated with allodynia or hyperalgesia. Before any intervention, visual analogue scale assessment ranged from 20-70\% of the full scale, depending on patients. Ventilatory autonomy was consistently achieved in group 1 and in two Group 2 patients $(\mathrm{p}=0.166)$. Persistent hypoventilation was not noted in group 1 but present in three group 2 patients $(\mathrm{p}=0.047)$. Correction of pulmonary hypertension was achieved irrespectively of the stimulation technique (one case in each group). One patient (patient 6) who was prescribed pregabalin to improve pacing tolerance developed cytolytic hepatitis requiring a change in treatment.

Although the observations were gathered over a long period of time, the pre-implantation procedures, the surgical procedures and the follow-up procedures were invariant. All the patients were tested by the same investigators, the stimulators were implanted by a single surgeon for each technique, and the follow-up was standardised at a single centre. In addition, the intradiaphragmatic series was "bracketed" by the intrathoracic series. We, therefore, believe that the length of the observation span (that is easily explained by the unique nature of the cohort; to our knowledge, there is no description of a similar case series of adult hypoventilation patients in the literature) is not a significant source of bias.

The phrenic nerve is a mixed nerve. It carries afferents from the subdiaphragmatic peritoneum (liver and spleen), pericardium, lower regions of the pleura, and the diaphragm [9]. Clinically, phrenic afferents irritation translates in referred neck and shoulder pain (C3-C5 sensory territory, Kehr's sign) [10]. Our observations are compatible with this mechanism. Phrenic nerve afferents comprise diaphragmatic C-fibres [11]. These small unmyelinated fibres have a high excitation threshold; they are not likely to be depolarised by the low-intensity currents used for intrathoracic phrenic stimulation (maximum $2.2 \mathrm{~mA}$ in table 1) that are permitted by the close electrode-nerve proximity. We hypothesise that, in contrast, the higher stimulation intensities (table 1) required to achieve intradiaphragmatic phrenic stimulation, because of a greater electrode-nerve distance, were sufficient to depolarise C-fibres in the vicinity of the electrodes and induce pain. In line with this, analgesic drugs known to be efficient on neuropathic pain (pregabalin, gabapentin and duloxetine) proved useful in our patients. Reducing stimulation intensities also proved useful but compromised pacing efficiency; even though the frequency of ventilatory autonomy was not statistically different between groups, persistent hypoventilation was significantly more frequent in group 2. Diaphragm pacing associated pain has not been reported with intrathoracic phrenic stimulation except in cases of device dysfunction [12]. Intradiaphragmatic phrenic nerve stimulation-related "discomfort" [13] or overt pain [14], have been described in clinical trials of diaphragm pacing in amyotrophic lateral sclerosis. In this context, phrenic stimulation does not aim at achieving ventilation but at diaphragm conditioning; it is delivered at lower intensities that can be further decreased to control pain. Yet the occurrence of pain in this setting confirms the reality of the issue. We also observed pain during intradiaphragmatic phrenic stimulation in two quadriplegic patients with incomplete spinal cord lesions. Of note, blunted pain perception has been described in congenital central hypoventilation syndrome (CCHS) children $[4,15]$ and could have contributed to the lack of pain reported in the two CCHS patients in group 1. Yet the other patients in this group did not have pain perception issues and the CCHS patient in group 2 did experience severe pain.

In conclusion, our observations should be borne in mind when choosing a diaphragm pacing technique in patients with functional sensory pathways. The advantages of intradiaphragmatic phrenic pacing could indeed then be offset by tolerance issues. Future technical developments of intradiaphragmatic phrenic stimulation should focus on stimulation protocols preserving stimulation of motor fibres while avoiding C-fibres stimulation. Unreported preliminary data suggest that modified pulse modulation schemes could achieve this, but this will need to be specifically studied. Of importance, future other mini-invasive diaphragm pacing techniques, such as transvenous phrenic stimulation [16], should be scrutinised for 
tolerance outside the particular quadriplegia context and particularly if diaphragm pacing indications widen, e.g. as an adjunct to mechanical ventilation in intensive care unit patients [17]. without spinal lesions http://ow.ly/IItjY

Capucine Morélot-Panzini ${ }^{1,2,3}$, Françoise Le Pimpec-Barthes ${ }^{4}$, Fabrice Menegaux ${ }^{5}$, Jésus Gonzalez-Bermejo ${ }^{1,2,3}$ and Thomas Similowski ${ }^{1,2,3}$

${ }^{1}$ Sorbonne Universités, UPMC Univ Paris 06, UMR_S 1158 Neurophysiologie Respiratoire Expérimentale et Clinique, Paris, France. ${ }^{2}$ INSERM, UMR_S 1158 Neurophysiologie Respiratoire Expérimentale et Clinique, Paris, France. ${ }^{3}$ Dept. R3S,AP-HP, Groupe Hospitalier Pitié-Salpêtrière Charles Foix, Service de Pneumologie et Réanimation Médicale (Département "R3S"), Paris, France. ${ }^{4}$ AP-HP, Hôpital Européen Georges Pompidou, Service de Chirurgie Thoracique, Paris, France. ${ }^{5}$ AP-HP, Groupe Hospitalier Pitié-Salpêtrière Charles Foix, Service de Chirurgie Viscérale, Paris, France.

Correspondence: Capucine Morélot-Panzini, Service de Pneumologie et de Réanimation Médicale, Groupe Hospitalier Pitié-Salpêtrière Charles Foix - Division Montyon, 47-83 Bd de l'Hôpital, 75651 Paris Cedex 13, France.

E-mail: capucine.morelot@psl.aphp.fr

Received: Nov 292014 | Accepted after revision: Jan 032015 | First published online: April 212015

Support statement: This work was supported by the programme "Investissement d'Avenir ANR-10-AIHU 06" of the French Government and the non-profit research association Association pour le Développement et l'Organisation de la Recherche en Pneumologie et sur le Sommeil (ADOREPS), Paris, France. Some of the patients described were included in a study of diaphragm pacing supported by grant DRC98075 from the Programme Hospitalier de Recherche Clinique National of the French Ministry of Health and of which the sponsor was the Direction de la Recherche Clinique, Assistance Publique-Hôpitaux de Paris, Paris, France. Funding information for this article has been deposited with FundRef

Conflict of interest: Disclosures can be found alongside the online version of this article at erj.ersjournals.com

Acknowledgements: The authors are grateful to Paul Robinson for editing English style and grammar.

\section{References}

1 Hirschfeld S, Exner G, Luukkaala T, et al. Mechanical ventilation or phrenic nerve stimulation for treatment of spinal cord injury-induced respiratory insufficiency. Spinal Cord 2008; 46: 738-742.

2 Le Pimpec-Barthes F, Gonzalez-Bermejo J, Hubsch JP, et al. Intrathoracic phrenic pacing: a 10-year experience in France. J Thorac Cardiovasc Surg 2011; 142: 378-383.

3 Romero FJ, Gambarrutta C, Garcia-Forcada A, et al. Long-term evaluation of phrenic nerve pacing for respiratory failure due to high cervical spinal cord injury. Spinal Cord 2012; 50: 895-898.

4 Weese-Mayer DE, Berry-Kravis EM, Ceccherini I, et al. An official ATS clinical policy statement: congenital central hypoventilation syndrome: genetic basis, diagnosis, and management. Am J Respir Crit Care Med 2010; 181: 626-644.

5 DiMarco AF. Phrenic nerve stimulation in patients with spinal cord injury. Respir Physiol Neurobiol 2009; 169: 200-209.

6 Hirschfeld S, Vieweg H, Schulz AP, et al. Threshold currents of platinum electrodes used for functional electrical stimulation of the phrenic nerves for treatment of central apnea. Pacing Clin Electrophysiol 2013; 36: 714-718.

7 Onders RP, Elmo MJ, Ignagni AR. Diaphragm pacing stimulation system for tetraplegia in individuals injured during childhood or adolescence. J Spinal Cord Med 2007: 30; Suppl. 1, S25-S29.

8 Morelot-Panzini C, Gonzalez-Bermejo J, Straus C, et al. Reversal of pulmonary hypertension after diaphragm pacing in an adult patient with congenital central hypoventilation syndrome. Int J Artif Organs 2013; 36: 434-438.

9 Kostreva DR, Pontus SP. Hepatic vein, hepatic parenchymal, and inferior vena caval mechanoreceptors with phrenic afferents. Am J Physiol 1993; 265: G15-G20.

10 Orr TG. Importance of phrenic shoulder pain in disease involving the diaphragm. JAMA 1923; 80: 1434-1436.

11 Balkowiec A, Kukula K, Szulczyk P. Functional classification of afferent phrenic nerve fibres and diaphragmatic receptors in cats. J Physiol 1995; 483: 759-768.

12 Weese-Mayer DE, Hunt CE, Brouillette RT, et al. Diaphragm pacing in infants and children. J Pediatrics 1992; 120: $1-8$.

13 Food and Drug Administration. NeurRx DPS diaphragm pacing system - H100006. http://www.accessdata.fda.gov/ scripts/cdrh/cfdocs/cftopic/pma/pma.cfm?num=h100006 Date last accessed: November 25, 2014. Date last updated: November 23, 2011.

14 Gonzalez-Bermejo J, Morélot-Panzini C, Salachas F, et al. Diaphragm pacing improves sleep in patients with amyotrophic lateral sclerosis. Amyotroph Lateral Scler 2012; 13: 44-54.

15 Vanderlaan M, Holbrook CR, Wang M, et al. Epidemiologic survey of 196 patients with congenital central hypoventilation syndrome. Pediatr Pulmonol 2004; 37: 217-229.

16 Hoffer JA, Tran BD, Tan JK, et al. Diaphragm pacing with endovascular electrodes. In: Mandl T, Martinek J, Bijark M, et al., eds. Proceedings of the 10th Vienna International Workshop on Functional Electrical Stimulation and 15th International Functional Electrical Stimulation Society Conference, 2010. Vienna, Center for Medical Physics and Biomedical Engineering Medical University of Vienna, Vienna Medical School, 2010; pp. 40-42.

17 Masmoudi H, Coirault C, Demoule A, et al. Can phrenic stimulation protect the diaphragm from mechanical ventilation-induced damage? Eur Respir J 2013; 42: 280-283. 